Benno Heussen

Letter of Intent 



\section{of Intertert}

Absichtserklärungen

Geheimhaltungsvereinbarungen

Optionen Vorverträge

von

\section{Prof. Dr. Benno Heussen}

Rechtsanwalt in Berlin

unter Mitarbeit von

Dr. Gerhard Pischel LL.M. (Univ. London)

Dr. Markus Junker

Dr. Dirk von dem Knesebeck

Rechtsanwälte in München

2. Auflage

2014

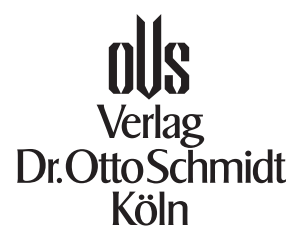


Bibliografische Information

der Deutschen Nationalbibliothek

Die Deutsche Nationalbibliothek verzeichnet diese Publikation in der Deutschen Nationalbibliografie; detaillierte bibliografische Daten sind im Internet über http://dnb.d-nb.de abrufbar.

Verlag Dr. Otto Schmidt KG

Gustav-Heinemann-Ufer 58, 50968 Köln

Tel. 02 21/9 37 38-01, Fax 02 21/9 37 38-943

info@otto-schmidt.de

www.otto-schmidt.de

ISBN 978-3-504-65909-7

C2014 by Verlag Dr. Otto Schmidt KG, Köln

Das Werk einschließlich aller seiner Teile ist urheberrechtlich geschützt. Jede Verwertung, die nicht ausdrücklich vom Urheberrechtsgesetz zugelassen ist, bedarf der vorherigen Zustimmung des Verlages. Das gilt insbesondere für Vervielfältigungen, Bearbeitungen, Übersetzungen, Mikroverfilmungen und die Einspeicherung und Verarbeitung in elektronischen Systemen.

Das verwendete Papier ist aus chlorfrei gebleichten Rohstoffen hergestellt, holz- und säurefrei, alterungsbeständig und umweltfreundlich.

Einbandgestaltung: Jan P. Lichtenford, Mettmann

Satz: WMTP, Birkenau

Druck und Verarbeitung: Betz, Darmstadt

Printed in Germany 